\title{
Ciberactivisme contra les violències sexuals: \#BringBackOurGirls
}

\author{
Ana M. González Ramos \\ UNIVERSIDAD PABLO DE OLAVIDE

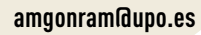 \\ ORCID: 0000-0003-1808-0291 \\ Beatriz Revelles-Benavente \\ UNIVERSIDAD DE GRANADA \\ beatrizrevellesRugr.es \\ ORCID: 0000-0003-1334-6257
}

\author{
Verònica Gisbert-Gracia \\ UNIVERSITAT DE VALÈNCIA \\ veronica.gisbert[auv.es \\ ORCID: 0000-0003-4867-2167
}

Rebut: 20/01/2020

Acceptat: 05/10/2020

\section{RESUM}

En els últims anys, les campanyes digitals s'han convertit en eines potents de denúncia i defensa de les violències contra les dones. El seguiment massiu en demostra l'èxit. No obstant això, continuem preguntant-nos sobre els límits i les oportunitats d'aquests instruments, especialment en àrees de conflicte i violència extrema. En aquest article, a través d'una etnografia digital i de l'anàlisi de les dades de l'activisme en la xarxa social Twitter, explorem l'impacte de la campanya \#BringBackOurGirls, que es va iniciar per a reclamar l'alliberament de 276 xiquetes segrestades pel grup terrorista nigerià Boko Haram a la ciutat de Chibok. Els resultats de la nostra investigació indiquen que la campanya s'ha centrat en un grup de xiquetes (les xiquetes de Chibok) sense tindre en compte la situació vulnerable de moltes altres xiquetes i dones joves al país.

Paraules clau: violència extrema, cibercampanyes, violències de gènere, postcolonial.

ABSTRACT. Cyber-Activism Against Sexual Violence: \#BringBackOurGirls

Over the last few years, many successful campaigns have both denounced women's vulnerabilities and protested against gender violence. The success of these campaigns can be gauged by the number of their followers, spreading the message and involving celebrities and agencies around the world. Those campaigns have put gender inequality and women's protests against sexual abuse firmly on the agenda. However, this still raises questions as to both the limits to and opportunities for cyber-activism in general and in strife-ridden areas in particular. This paper addresses the influence of digital campaigns against sexual violence, exploring the impact of the \#BringBackOurGirls campaign, which covers the kidnapping of a large group of girls in Nigeria by the Boko Haram terrorist group. Among other things, we find that the campaign narrowly focused on a group ('The Chibok Girls'), ignoring the vulnerability of many other girls and young women in Nigeria.

Keywords: extreme violence, digital campaigns, gendered violence, post-colonial. 


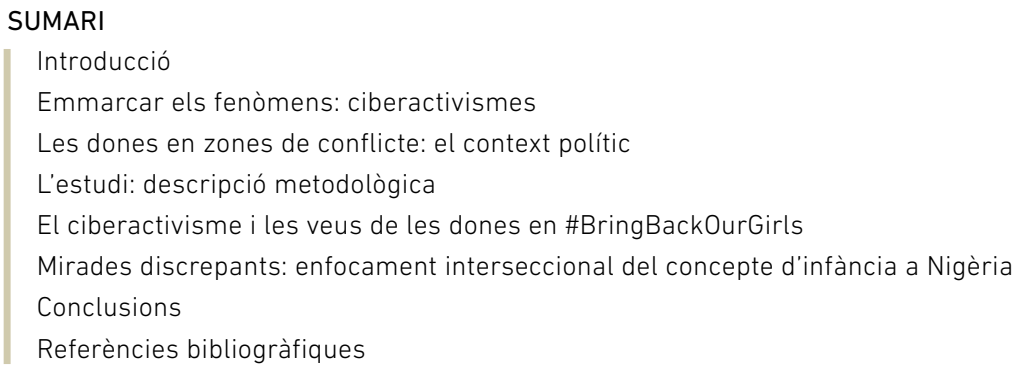

Autor per a correspondència / Corresponding author: Ana M. González Ramos, Facultad de Ciencias Sociales (Universidad Pablo de Olavide). Conde de Aranda Ctra. De Utrera, Km. 1, 41013, Sevilla (Espanya).

Citació suggerida / Suggested citation: González Ramos, A. M., Revelles-Benavente, B., Gisbert-Gracia, V. Ciberactivisme contra les violències sexuals: \#BringBackOurGirls. Debats. Revista de cultura, poder i societat, 134(2), 29-41. DOI: http://doi.org/10.28939/iam.debats.134-2.3

\section{INTRODUCCIÓ}

Tradicionalment, el dret civil internacional ha sigut un moviment transnacional inclusiu amb els moviments pels drets de les dones. En els últims anys, la velocitat comunicativa s'ha incrementat per mitjà de campanyes digitals (Bunch, 2001; Riles, 2002), que apareixen com un instrument potent per a la denúncia i la defensa de les violències contra les dones. L'activisme digital contemporani ha creuat les fronteres geogràfiques i culturals de les comunitats locals i ha articulat també els moviments feministes (Cockburn, 1998; Friedman, 2016). Així doncs, moltes campanyes han denunciat les vulnerabilitats de les dones i s'han transformat en una veu unificada contra les violències de gènere.

A tall d'exemple, trobem les campanyes \#BringBackOurGirls, \#StopRapeInConflict, \#NiUnaMenos i \#MeToo, l'èxit de les quals queda demostrat per la quantitat de seguidors, l'abast global dels missatges i les celebritats i agents involucrats. Els ciberactivismes feministes han introduït una agenda de gènere que inclou els abusos sexuals en diversos escenaris (governs, organitzacions, indústria del cine, etc.). No obstant això, desconeixem l'impacte real d'aquestes campanyes en les comunitats locals i en les realitats de les xiquetes i dones que reben el suport de la mobilització global. En aquest article ens interessa particularment conéixer l'impacte de les cibercampanyes en la vida de les dones i xiquetes en àrees de conflicte bèl-lic, a causa de la falta d'informació i la complexitat de les relacions de poder desenvolupades en aquests territoris. En conseqüència, posem el focus en els rols de les dones, en concret, de les xiquetes i dones joves en situacions de violència extrema (Anderlini, 2018) des d'una perspectiva agencial, és a dir, no sols com a cossos vulnerables, sinó també com a agents i activistes digitals.

Cada vegada és més habitual l'emergència pública de trobar adolescents com a models inspiradors tant per a la població juvenil com per a l'adulta. Així doncs, Malala Yousafzai, Premi Nobel de la Pau i capdavantera del dret a l'educació de les xiquetes, o Greta Thunberg, activista adolescent sueca contra el canvi climàtic, són figures reconegudes a escala 
global. Elles s'han convertit en narradores de les seues realitats, aportant la seua experiència i idees inspiradores que emmarquen la seua generació (Bent, 2016). A més, els canals de difusió de discursos i idees i d'interacció amb els seus seguidors que utilitzen -és a dir, les xarxes socials- són els característics de les generacions que les defineixen.

No obstant això, com a membres de societats patriarcals i malgrat els lideratges descrits, les xiquetes i les joves poden ser víctimes de les pràctiques de persones adultes, especialment en situacions d'especial vulnerabilitat i conflicte. Així mateix, com a dones, són utilitzades com a armes de guerra contra els enemics i els seus cossos són instrumentalitzats pels exèrcits, familiars i parelles. Per aquest motiu sovint les xiquetes suporten situacions de violència diverses segons l'origen social, les arrels geogràfiques i el grup ètnic a què pertanyen, perquè, com va afirmar Braidotti (1994) sobre les adultes, aquestes no són un grup homogeni. Convertir-se en una dona des de la infància també és un factor processal que difereix segons les oportunitats que envolten cadascú.

Aquest article es divideix en quatre seccions. Després d'aquesta introducció, la discussió teòrica presenta el marc de l'activisme digital i el paper de les xiquetes i les dones en àrees de conflicte dins d'eixes campanyes. La següent secció descriu els objectius i la metodologia duta a terme pel grup d'investigació. Les següents seccions relacionen els resultats de la nostra anàlisi, que comprén el paper de la dona en les àrees de conflicte i, específicament, en les campanyes digitals, així com la discussió de les fortaleses i els límits de les campanyes digitals. Finalment, presentem un resum i algunes idees per a guiar les campanyes d'activistes que tracten amb xiquetes en àrees de conflicte. La secció final també inclou algunes idees sobre bones pràctiques per al moviment social en les xarxes socials.

\section{EMMARCAR ELS FENÒMENS: CIBERACTIVISMES}

Pel que fa a la participació digital, Claudia Mitchell (2017) explica que «les plataformes de xarxes socials estan fermament arrelades en la vida quotidiana de molts joves de tot el món». De fet, per a ells tenen múltiples usos, com ara compartir imatges, pensaments o, fins i tot, conéixer la seua sexualitat (Ringrose i Eriksson, 2011; boyd, 2014; Bustillos, 2017). A més, Garrett (2006) i Carter Olson (2016) agreguen que les eines digitals aporten visibilitat, mobilitzen les forces socials i promouen una resposta immediata $i$ àmplia, de manera que es converteixen en instruments influents de les polítiques públiques.

Segons Castells (2011: 11), el ciberactivisme és una extensió dels moviments socials tradicionals, un recurs nou i poderós que permet arribar a una comunitat global que persegueix un objectiu. Per tant, internet es converteix en un fòrum de deliberació que estén els drets civils, però que també experimenta amb aquests drets i amplia els límits entre la llibertat i el discurs, l'arena política i l'activisme. En contra d'això, no podem ignorar algunes crítiques sobre aquestes pràctiques. En aquesta línia, Annelisse Riles (2002: 302) adverteix que la sobreexposició a les campanyes de drets civils produeix una audiència insensible, inevitablement perjudicada per nombrosos objectius i una problematització descontextualitzada. L'activisme digital pot convertir-se en una pràctica postcolonial, ja que si no se satisfan les preocupacions de la ciutadania occidental, els actors locals i les seues veus poden passar desapercebuts en aquestes campanyes globals.

A més, Charlotte Bunch (2001: 145) suggereix que l'activisme social no és coherent ni homogeni, ja que l'activisme digital s'embolica en conflictes i disputes de base, és a dir, hi ha diverses situacions en la societat global que afegeixen complexitats, com les zones de guerra, les zones de pobresa, els conflictes ètnics i religiosos, l'escassa accessibilitat digital i les desigualtats socials (Mohanty, 1991; Khoja-Moolji, 2015; Maxfield, 2016). Atenent a aquestes realitats plurals, la diversitat cultural i els entorns socials diferents, sorgeix la pregunta següent: Qui gestiona el missatge i quina diversitat de veus inclou aquest tipus de campanyes? El debat obert sobre l'articulació internacional i local de les campanyes virtuals és 
només una de les dimensions d'aquesta complexa qüestió. Els acadèmics i les acadèmiques - i activistes- han de plantejar-se la realitat de veus incòmodes en un mateix conflicte, l'accés als instruments de comunicació dels grups vulnerables i dels agents locals. En definitiva, qui sustenta els missatges i la direcció de les campanyes digitals? Però, sobretot, quines consequències provocaran a llarg termini per a les persones involucrades?

Les xarxes socials també introdueixen un nou concepte de les accions, una «suspensió del present» (Coleman, 2018) que implica una temporalitat diferent en el desenvolupament d'aquestes campanyes. La temporalitat en els mitjans digitals segueix el seu propi procés, que té conseqüències particulars en les causes d'aquestes campanyes. El contínuum entre allò local i allò global es converteix en part de la mateixa moneda en les xarxes socials, com una mescla de passat, present i futur (Coleman, 2018). Aquest «present suspés» determina la vida de les xiquetes i joves de la nostra investigació, les quals es transformen en dones amb el pas del temps. En aquest sentit, la campanya \#BringBackOurGirls va començar fa cinc anys amb el segrest de xiquetes amb edats compreses entre els 12 i els 16 anys. En aquests moments, les edats d'aquestes joves oscil.len entre els $17 \mathrm{i}$ els 21 anys, fet que associem materialment a la transició de xiqueta a dona en el pensament occidental. No obstant això, en la premsa occidental encara s'hi refereixen com «les xiquetes de Chibok», cosa que perpetua la seua condició de xiquetes i descuida el procés pel qual podrien haver passat durant aquests anys fins a convertir-se en dones. A més, no podem obviar que, als ulls no occidentals, la majoria d'elles ja eren considerades dones el dia del segrest (Mohanty, 1984).

Per tant, és important establir la genealogia d'aquesta campanya digital en particular. La campanya s'inicia amb un tuit de l'advocat nigerià Ibrahim Abdullahi en què fa al-lusió a un discurs públic de la Dra. Oby Ezekwesili, ministra d'educació nigeriana en aquell moment, en el qual reclama l'alliberament de les xiquetes segrestades d'una escola catòlica de Chibok, fet que reforça la idea que un canal masculí es fa d'eco de les veus de les dones per poder-hi arribar. Aquesta campanya sorgeix de la consciència ciutadana sobre les violències de gènere. En paraules de la Dra. Oby Ezekwesili —en una comunicació personal per a aquesta investigació-, l'èxit de la ciberacció promou l'atenció del govern nacional nigerià i de figures internacionals que fan que la qüestió aparega en les primeres planes dels informatius globals. Desafortunadament, aquesta atenció internacional també té un efecte bumerang, ja que el grup terrorista Boko Haram, després de l'atenció inesperada i la publicitat rebuda en les xarxes socials, reformula el segrest de les xiquetes en les escoles com una estratègia propagandística de la seua causa (Cox et al., 2018). En conseqüència, les joves de Chibok no van ser les últimes desaparegudes. A més, algunes d'eixes xiques de Chibok encara romanen amb el grup terrorista i no han tornat a casa.

\section{LES DONES EN ZONES DE CONFLICTE: EL CONTEXT POLIITIC}

El debat sobre els rols de les dones en contextos de conflicte i guerres és ampli (Enloe, 1989; Bloom, 2011; Magallón, 2010; Ponzanesi, 2014). L'assignació tradicional d'un paper passiu a les dones en temps de guerra s'oposa a l'èmfasi que des dels estudis de la pau i els conflictes feministes s'atorga a la importància de les comeses per les dones tant en els processos bèl-lics com en les fases posteriors de restabliment de la pau. Defenen que les dones sempre han actuat activament en les guerres, incloent-ne els rols de soldat o d'infermera, i les vindiquen com a agents imprescindibles per a la construcció de la pau, encara que aquest paper està invisiblilitzat en la història. Segons Ponzanesi (2014), l'ocultació de les pràctiques actives de les dones en els conflictes es propicia perquè quan els conflictes acaben, les dones tornen a casa. Aquest enfocament ens ajuda a emmarcar els rols representats per les dones en el context del terrorisme de Boko Haram.

Matfess (2017) ha detallat una pluralitat de comeses complexes exercides per les dones en l'àrea de con- 
flicte de Nigèria ${ }^{1}$, especialment en els campaments del grup insurgent, que abarquen des de ser les esposes dels combatents fins a la utilització dels seus cossos en operacions suïcides o com a reclutadores i agents d'intel-ligència. Al mateix temps, en algunes ocasions s'ha descrit el grup islàmic com a «amics» de les dones (Matfess, 2017: 57), ja que, aprofitant que es troben en una situació precària, ofereixen suport econòmic a les dones i les seues criatures. Igual que els homes, les dones joves prenen decisions vitals que les ajuden a pujar en l'escala social per a sobreviure i millorar les seues vides i les de les seues famílies. Segurament, als ulls dels occidentals, aquestes estratègies d'ascens social poden considerar-se desviades i incomprensibles, però la visió occidental (Mohanty, 1998) ens impedeix entendre que les dones estan responent (estan actuant per la seua pròpia capacitat de respondre dins d'estos límits opressius) a les seues pròpies circumstàncies de desigualtat de gènere i de violència extrema. No obstant això, la complexitat del conflicte es reflecteix no només en les violències perpetrades contra xiquetes $i$ dones pels insurgents, sinó, sinó també pel mateix exèrcit nigerià. L'abril de 2019, Amnistia Internacional va condemnar la violència sexual i de gènere comesa per soldats nigerians tant en les presons on estan confinades dones de Boko Haram com en els campaments de desplaçats habilitats per a acollir i protegir les persones que fugen del conflicte. Si situem els nostres antecedents teòrics en l'estudi de cas d'aquest article, és important destacar la complexitat de les històries de vida de les xiquetes que són violentades. La vida de les xiquetes a Nigèria varia molt segons la situació geogràfica —rural o urbanai la religió que professen, ja que la intersecció entre rural i musulmana s'ha identificat com un detriment en el seu desenvolupament vital (Maxfield, 2016).

No obstant això, la situació de les xiquetes a Nigèria va passar desapercebuda a escala mundial fins al

1 Boko Haram sorgeix i s'assenta al nord-oest de Nigèria, a l'estat de Borno. La divisió entre el sud i el nord de Nigèria està marcada per la pobresa i l'analfabetisme del nord respecte del sud del país. sorgiment de la cibercampanya analitzada en aquest article. Amb una gran difusió internacional, l'any 2014 nombrosos intel-lectuals i polítics van sol-licitar l'alliberament de 214 xiquetes cristianes segrestades a l'escola. Aquest atac violent va desvelar que les xiquetes $\mathrm{i}$ joves nigerianes, tant musulmanes com cristianes, són víctimes d'una repressió més àmplia com a resultat dels règims patriarcals i de gènere, així com dels conflictes econòmics, culturals i socials.

Segons Mandrona (2016: 8) «la infància sovint es concep en termes de les implicacions que té per a comprendre la feminitat en comptes de concebre's com una experiència i un tema d'investigació ètica derivada de dret propi». Això esdevé encara més rellevant quan agreguem les interseccions d'etnicitat i religió a l'equació. No sols hem de pensar que cada dona és diferent (Braidotti, 1994; Yuval-Davis, 2006), sinó que també la infància, com a experiència pròpia, és múltiple i les conseqüències de convertir-se en dona produeixen una complexitat particular. Més enllà d'això, pot considerar-se igual aquesta complexitat en temps de pau i en temps de guerra? Segons hooks (1986) hem d'abordar la interseccionalitat, que en aquest cas concret inclou la raça en el context del moviment de drets civils, la religió els entorns urbans/rurals i els contextos educatius i socioeconòmics com a factors rellevants per a les xiquetes nigerianes.

Per tant, les xiquetes i dones joves involucrades en aquest conflicte poden tindre diferents rols: víctimes (segrestades, víctimes del terrorisme amb bombes i violacions, etc.), protagonistes (membres del grup terrorista, esposes, mares), així com activistes socials contra les violències de gènere i la injustícia social (en el context local i internacional). Però, a més, a causa de l'enrenou internacional provocat per la cibercampanya, els cossos de les xiquetes segrestades s'han convertit en una valuosa moneda de canvi entre el govern federal i Boko Haram (Escola de Cultura de Pau, 2019), al mateix temps que són una peça clau de la política i els activismes feministes per a posar les violències sexuals en zones de conflicte sobre la taula de l'agenda de gènere internacional. 


\section{L'ESTUDI: DESCRIPCIÓ METODOLÒGICA}

La nostra investigació se centra a realitzar una aproximació a l'impacte de les campanyes digitals contra les violències sexuals contra xiquetes $i$ dones en àrees de conflicte. Amb aquest propòsit, l'estructura metodològica es constitueix en diferents fases: en primer lloc, es planteja un acostament geopolític a les realitats nigerianes i, en concret, als principals esdeveniments sociopolítics succeïts al país des del començament del segrest de Chibok fins al present; a continuació, s'avalua l'impacte de la campanya \#BringBackOurGirls pel que fa a les relacions de gènere en el context local i internacional i, finalment, s'analitza la participació femenina en aquesta campanya.

L'acostament al cas d'estudi es va fer a través de dades secundàries -informes, notícies dels mitjans i estudis acadèmics d'aquest conflicte produïts en el context geogràfic corresponent, però també al Nord Global- i per mitjà de l'anàlisi de contingut del hashtag de la cibercampanya i d'entrevistes a actors rellevants de Nigèria. Vam analitzar l'activisme en Twitter de \#BringBackOurGirls des d'octubre fins a desembre de 2014, i les conseqüències polítiques d'aquest moviment fins a l'actualitat. L'anàlisi del missatge i els discursos polítics al voltant d'aquest hashtag es troben en el marc d'aquest estudi, ja que les xiquetes són els temes principals d'aquests missatges. Atés que la campanya va ser creada des de la societat civil nigeriana $\mathrm{i}$ àmpliament difosa per la comunitat internacional, també incloem les aportacions d'entrevistes realitzades a Nigèria a activistes locals i globals. Parlem amb ells sobre com lluitar contra les violències de gènere a través de la mobilització digital, sobre la seua participació en la campanya \#BringBackOurGirls i l'opinió que en tenen.

A més, oferim un enfocament interseccional perquè el que entenem per xiquetes o dones joves en aquestes àrees conflictives esdevinga més complex. Particularment, en partim de les necessitats de YuvalDavis (2006: 200) d'incloure:

Diversos tipus de diferències en la nostra anàlisi [per tal que] puguem evitar la combinació de posicionaments, identitats i valors. També podem evitar atribuir agrupacions d'identitat fixa a la dinàmica de processos de posicionament $\mathrm{i}$ ubicació, d'una banda, i a la construcció política controvertida i canviant de límits categòrics, de l'altra.

\section{EL CIBERACTIVISME I LES VEUS DE LES DONES EN \#BRINGBACKOURGIRLS}

Després de cinc anys de campanya, la història de \#BringBackOurGirls, tant en línia com en la vida real, ens aporta lliçons interessants, per la continuïtat de la campanya en el temps i per les conseqüències materials que ha tingut, ja siga a nivell local o global.

Des del nostre punt de vista, representa un cas d'estudi exemplar pel que fa a les protestes d'activistes locals en diferents sentits: per l'àmplia mobilització, el gran impacte internacional i l'elevada participació de figures rellevants de les arts i la política mundial. També és exemplar si atenem als beneficis obtinguts localment, ja que suposa un gran reconeixement. Des del punt de vista geopolític, la campanya provoca un impacte en el govern i l'administració interna de Nigèria: en primer lloc, la pèrdua de la presidència de Goodluck Ebele Azikiwe Jonathan en les eleccions de març de 2015 (Carter Olson, 2016); en segon lloc, la materialització de mesures legislatives i accions militars per a combatre la corrupció i el terrorisme per part del nou president nigerià, Muhammadu Buhari (Comolli, 2015) i, en tercer lloc, una tímida inclusió de polítiques de gènere en l'agenda política nacional, encara que amb un impacte reduï, ja que la bretxa de gènere persisteix (Matfess, 2017).

D'altra banda, \#BringBackOurGirls ha promogut reaccions internacionals. Durant el nostre estudi observem aspectes positius i negatius d'aquest focus internacional. Hi ha una atenció creixent als problemes de Nigèria $i$, en particular, a aquells que tenen a veure amb la infància $i$ les dones en zones de conflicte bèl-lic. Cal mencionar que la infància ha 
sigut el centre d'atenció de la comunitat internacional des de la Convenció sobre els Drets de l'Infant (Assemblea General de l'ONU, 2001) i el seu Protocol facultatiu relatiu a la participació d'infants en els conflictes armats. Així mateix, el Consell de Seguretat de les Nacions Unides, per mitjà de les resolucions $1261,1314,1379,1460,1539,1612,1882,1998$, 2068 i 2143 , ha contribuït a crear un marc integral per a abordar la protecció de les criatures afectades pels conflictes armats. No obstant això, no és fins la Resolució 2225 del 18 de juny de 2015 (Consell de Seguretat de l'ONU, 2015) quan s'expressa la «greu preocupació pel segrest de xiquets i xiquets en situacions de conflicte armat». Així doncs, si llegim amb atenció la resolució i l'ubiquem en l'any en què es va aprovar, podríem suposar que el segrest de les xiquetes de Chibok, però, sobretot, l'impacte que va generar l'inici de la campanya digital analitzada en aquest article, va ser un catalitzador de la resolució. Precisament perquè si llegim el text de la resolució, es descriuen de forma anàloga les autories dels segrestos esmentats, els llocs on poden produir-se i els abusos dels drets humans i les violacions del dret internacional humanitari comeses per «grups armats no estatals, en particular grups extremistes violents» (Consell de Seguretat de l'ONU, 2015).

No obstant això, al mateix temps la campanya va generar un efecte propagandístic de les activitats del grup terrorista Boko Haram i, com es menciona en l'epígraf anterior, el valor dels cossos de les joves segrestades s'ha potenciat i les xiquetes s'han convertit en una valuosa moneda de canvi per tal de pressionar el govern federal i negociar amb ell. Cal afegir que, tot i que una gran majoria de les joves segrestades aquell 14 d'abril segueixen desaparegudes, un grup reduït va ser rescatat a canvi de l'alliberament d'alguns membres presos del grup terrorista per part del govern. En conseqüència, les xiquetes i dones nigerianes continuen estant subordinades a les injustícies patriarcals i socials i els seus cossos continuen sent utilitzats i objectificats en el conflicte. Dit això, cal remarcar que \#BringBackOurGirls reflecteix les veus femenines del conflicte, ja que el hashtag prové del discurs d'una dona nigeriana, Oby Ezekwesili.
Arribats a aquest punt, en aquesta campanya trobem avanços i retrocessos pel que fa a qüestions importants relacionades $\mathrm{amb}$ la violència de gènere en àrees de conflicte, conscients del maneig de situacions complexes i la diversitat de grups conflictius. En primer lloc, les joves de Chibok podrien adaptar-se a la situació i convertir-se en dones segons els paràmetres del grup terrorista, per a perpetuar els rols de víctimes en aquest conflicte. En segon lloc, les dones participen en la campanya local i mundial amb un paper actiu, tot i adoptar una postura crítica. Maxfield (2016), junt amb molts intel-lectuals, ha denunciat la sobreexposició de les xiquetes durant la campanya. El missatge \#BringBackOurGirls expressa les preocupacions de la ciutadania per la utilització dels cossos de les xiquetes, però, a més, alguns activistes nigerians, com ara l'escriptor Teju Cole, reclamen que el cas de les xiquetes segrestades es recontextualitze en la política interna i que el poble nigerià puga recuperar-les, ja que, a causa de la campanya internacional, s'han transformat en símbols passius de la campanya de mobilització internacional. Com déiem en la introducció d'aquest article, les experiències d'aquestes joves són úniques, raó per la qual suggerim un examen ètic de les campanyes digitals que estiga en línia amb el seu propi esdevenir per a evitar un estat de victimització permanent.

Durant aquests cinc anys, algunes persones locals han qüestionat l'abast de la campanya \#BringBackOurGirls. Activistes nigerians denuncien que, en posar el focus mediàtic internacional en les xiquetes de Chibok, s'ha invisibilitzat la situació de les xiquetes nigerianes en termes generals. Així mateix, demanen més atenció cap a les xiquetes musulmanes, que corren un risc superior pel fet de procedir de contextos més pobres i vulnerables, majoritàriament comunitats sense educació (Mahmood, 2017). Dos dones de la població civil nigeriana entrevistades en aquest estudi assenyalen que la campanya va marcar una diferència a Nigèria quant a les realitats de les xiquetes i dones, però lamenten que aquesta atenció es limite a les xiquetes de Chibok i reclamen un abast més ampli de la situació de les dones al 
país. Per tant, les xiquetes a les quals es defén en les xarxes socials occidentals són les xiquetes de Chibok —que resulten ser cristianes i escolars-, mentre que les xiquetes musulmanes i analfabetes que viuen en zones rurals i pobres són ignorades. L'educació i el reforç del paper de les xiquetes a Nigèria sorgeixen com una acció principal a Àfrica per tal de previndre la violència i la discriminació de gènere. Però, a més, en el cas concret que ens ocupa, seria una eina efectiva de prevenció per a evitar que elles i els seus familiars se sumen a la causa de Boko Haram.

Un tema addicional en aquesta anàlisi és la neocolonització occidental, ja que la intervenció d'actors occidentals té un impacte directe en la política nigeriana. Una de les informadores s'ha referit a la imatge negativa del president Goodluck al món pel cas Chibok, i com aquest fet va influir en la seua pèrdua de les eleccions. A aquests esdeveniments històrics podem sumar la renúncia d'Oby Ezekwesili —que va ser l'actora més visible de la campanya \#BringBackOurGirls - com a candidata a la presidència en les últimes eleccions de 2019 perquè no va obtindre els suports necessaris per a arribar-hi. Sembla que la ciutadania nigeriana exigeix una acció que tinga en compte les realitats particulars i les conseqüències específiques, sense imposició d'ideologies occidentals.

En conseqüència, per a dissenyar campanyes digitals ètiques, hem d'evitar atribuir als subjectes que són el focus d'atenció identitats fixes o - pitjor encara- occidentalitzar-los i ser conscients de les possibles pràctiques postcolonials. L'anàlisi empírica de \#BringBackOurGirls mostra una mirada restringida, ja que els informadors afirmen que només es focalitza en les joves de Chibok i ignora la resta de les xiquetes afectades per aquesta violència extrema.

Pel que fa al discurs postcolonial, aquesta campanya n'és un bon exemple, pel fet que va ser iniciada per part d'agents locals i que la reacció de la comunitat internacional va limitar-se a recolzar l'acció principal. A més, els actors nigerians han advertit en diferents punts de la campanya que els actors no nigeri- ans tenen una posició subordinada i destaquen el paper principal dels líders i ciutadania nigeriana per a gestionar el problema intern.

No obstant això, en analitzar discursivament el missatge que representa la campanya - torneu-nos les nostres xiquetes- podem observar la reproducció de patrons de protecció en defensa de les víctimes menors. Centrem l'atenció en el fet que han sigut segrestades per ser xiquetes cristianes i educades. Boko Haram vol convertir-les a l'islam perquè arriben a ser bones esposes i mares. Com s'ha indicat anteriorment, aquesta campanya porta cinc anys en marxa i, quan van ser segrestades, tenien entre 12 i 16 anys. De la mateixa manera, els factors interseccionals posen sobre la taula la necessitat d'una definició situacional de les xiquetes en la discussió: són xiquetes per a qui? Són xiquetes per a les seues famílies i comunitats, però no per al grup terrorista? Com es defineixen a elles mateixes? Continuen sent xiquetes després dels intolerables successos que han patit i fins i tot simplement per estar contínuament sota l'amenaça de ser segrestades?

\section{MIRADES DISCREPANTS: ENFOCAMENT INTERSECCIONAL} DEL CONCEPTE D'INFÀNCIA A NIGÈRIA

Fins ara, Nigèria no ha avançat massa en igualtat de gènere ni en cap altre tipus d'igualtat, ja que, segons Oxfam International (Mayah et al., 2017), ocupa l'última posició d'entre 152 països en quant a interés per reduir la desigualtat. La pobresa i la desocupació ja s'han definit com a forces impulsores per al reclutament del terrorisme. Botha i Abdile (2019) expliquen que la participació en grups insurgents ofereix algunes recompenses econòmiques i oportunitats de matrimoni per a les persones joves que viuen en situacions de pobresa i violència extrema.

La desocupació s'assenyala com la causa de l'adhesió juvenil a l'extremisme a Nigèria (Comolli, 2015; Ordu, 2017) i les accions militars del govern per a combatre la insurrecció també contribueixen al sentiment d'inseguretat en el context geogràfic 
en què opera Boko Haram. Els joves —incloses les xiquetes i les dones joves- que creixen en contextos d'extrema violència i pobresa es transformen en objectius i participants de les accions dels grups insurrectes.

La situació de les xiquetes i dones nigerianes prové de la desigualtat de gènere i la cultura patriarcal. Tot i els recursos naturals i el creixement econòmic en les últimes dècades, la taxa de pobresa no ha disminuït, i més del $62 \%$ (180 milions de persones) encara vivien en situació de pobresa extrema a l'any 2017. El 2013, l'índex de Gini 48,8, va situar Nigèria en la posició 21 en desigualtat entre tots els països del món, i la situació continua empitjorant segons l'informe d'Oxfam esmentat: Nigèria ocupa l'últim lloc en la llista dels 152 països que no tenen compromís per a reduir la desigualtat. Paral-lelament, els indicadors de gènere mostren que ser dona a Nigèria comporta precarietat. L'escolaritat mitjana màxima és de nou anys, però la taxa femenina és de huit. La taxa de mortalitat és de 9,6 per cada 1.000 habitants, però la mortalitat materna és de 917 per cada 100.000 naixements vius (2017). La situació a les zones rurals esdevé més complexa, ja que s'espera que les xiquetes es casen i esdevinguen mares als 16 anys, un matrimoni negociat entre els membres masculins de la família a canvi d'un dot, tradició encara vigent al país africà. Les dones no poden accedir a la propietat de les terres, tot i que són elles qui més les cultiven, fet que limita les seues oportunitats econòmiques i estratègies de supervivència. El valor de les dones i els seus cossos és tan escàs que, per exemple, Matfess (2015: 166) va citar la devaluació del preu de les dones en el mercat del tràfic de persones i la prostitució a Nigèria.

Tanmateix, malgrat les dades exposades, les xiquetes i les dones són un grup heterogeni amb rols diversos.Tenint tot això en compte, una nova pregunta s'afig al debat sobre la definició d'agència. Segons Mandrona (2016: 3), les xiquetes poden ser «sistemàticament discriminades, però també [...] com a actors socials capaços, que influeixen i són influenciats pel món en què viuen».
No obstant això, com poden dur a terme la seua agència aquestes xiques i dones vivint en llocs violents i foscos? Poden actuar amb autonomia i amb la seua pròpia veu? La vulnerabilitat dels menors pareix autoritzar la visió legítima de l'adult sobre les seues vides, ja que els cuiden i es centren en la seua edat i identitat.

Com s'ha explicat anteriorment, cal abordar l'enfocament interseccional des d'una doble perspectiva: qui pertany a la meua comunitat i com han intervingut els ulls occidentals en aquesta campanya. Per aquest motiu, aquest article també té l'objectiu de «produir [nous] imaginaris i maneres d'ésser humans ètics, sobre drets, alteritat, poder, agència i responsabilitat» (Mandrona, 2016: 3). Aquests imaginaris advoquen per una ètica relacional que incloga els agents locals com a part imprescindible del disseny de les campanyes polítiques per a promoure una agència relacional i la capacitat de resposta a la violència de gènere i erradicar així la cultura patriarcal.

Pel paper principal en la socialització i transmissió cultural que tenen les dones joves, també convé mostrar-les com a agents de consolidació de la pau (Enloe, 1989; Bloom, 2011; Magallón, 2020; Ponzanesi, 2014; Anderlini, 2018) i, per a això, cal examinar el paper de les dones joves en els contextos de violència extrema.

Botha i Abdile (2019) informen que es detecten diferències de gènere en el reclutament de dones com a membres del grup armat Boko Haram. Indiquen que un gran nombre de dones joves es van veure obligades a entrar en l'organització com a mares, esposes i soldats. Així mateix, els autors aconsellen que es tinga en compte l'impacte de la Síndrome d'Estocolm en la implementació posterior dels programes de consolidació de la pau per a la resocialització de les dones. Les dones insurrectes i les xiquetes segrestades estan implicades amb entorns de violència extrema, on desenvolupen estratègies de supervivència per a protegir-se i protegir les seues criatures. $\mathrm{Ni}$ tan sols perceben l'alliberament com el final del seu camí, sinó que l'entenen com un pas més: s'enfron- 
ten a noves vides que presenten nous desafiaments. Fins ara, la reintegració a la comunitat de les xiquetes rescatades és difícil a causa de l'estigma que els recau a sobre, sobre les seues famílies i sobre les criatures nascudes com a conseqüència de les violacions sofrides durant la captivitat.

Algunes associacions civils, com ara la Federació de Dones Musulmanes (FOMWAN), han llançat un programa d'educació i empoderament de xiquetes inspirat per aquest sentiment de debilitat del règim de gènere a l'Àfrica. Malgrat les opinions diverses expressades per les persones informadores entrevistades en aquest estudi, totes han mostrat la mateixa posició discursiva quant a l'obligació i l'esforç en l'empoderament de les xiquetes per afrontar el futur.

Mentre les dones joves siguen conscients de la seua pròpia situació de precarietat, exerciran rols d'acord amb la violència extrema que viuen i s'hi enfrontaran amb estratègies complexes. Això apunta a un fracàs massiu del context actual en què viuen les xiquetes $i$ les dones provocat pel patriarcat i la precarietat (falta d'educació i oportunitats, atenció del matrimoni i la maternitat com a única fortalesa de les dones).

Per descomptat, no podem —ni devem- desplaçar l'agència completa d'aquestes xiquetes i les seues comunitats, ja que la capacitat de resposta no depén d'elles individualment, sinó d'un entramat molt complex de poder, prestigi, vulnerabilitat, violència de gènere i, en general, aïllament. Per tant, hauríem de buscar una agència relacional que distingira les representacions polítiques en campanyes massives sobre les xiquetes i joves fins a convertir-se en dones durant temps particularment conflictius. Les campanyes digitals requereixen xarxes d'activistes intergeneracionals, de manera que l'empoderament ètic de les xiquetes implica el reconeixement compartit de les dones i les xiquetes com a «éssers encarnats concrets» (Benhabib, 1992: 189) amb accés limitat a la «intel-ligibilitat» política (Butler, 2009: xI) i al poder.

Així, segons la tesi de Mandrona, es requereixen nous imaginaris a partir de diàlegs intergeneracio- nals entre tots els actors que participen en aquest procés. Per això, per a concloure, presentem tres punts o recomanacions diferents amb l'objectiu de superar aquest problema: la definició interseccional de la infància, una agència relacional com a estratègia política feminista i un consens per a començar el disseny ètic i feminista glocal (local i global) d'una campanya digital.

\section{CONCLUSIONS}

Aquest article ha procurat reflexionar críticament sobre la complexitat de Nigèria i el desafiament de promoure la igualtat de gènere internacionalment i advertir sobre la violència de gènere en àrees de conflicte, especialment quan fa referència a xiquetes i dones joves. L'anàlisi d'aquest fenomen ha combinat enfocaments procedents de l'anàlisi dels esdeveniments històrics (dades secundàries), de la teoria feminista (interseccionalitat), dels estudis de comunicació (anàlisi de xarxes socials i anàlisi de contingut del missatge), del dret internacional (anàlisi discursiva de les legislacions de les Nacions Unides) i, finalment, però no per això menys important, d'un component filosòfic que requereix estendre l'ètica i l'agència més enllà dels ulls postcolonials.

Els resultats confirmen la utilitat de la campanya digital analitzada per a difondre la veu dels agents locals en general, que es converteixen en narradors de les seues comunitats, però també apareix el risc de simplificar el missatge i ocultar el panorama general que realment reflecteix la situació social.

En primer lloc, les xiquetes de Chibok són una mostra de la població de risc involucrada en el conflicte. El fet que foren xiquetes cristianes posa sobre la taula els interessos i les diverses posicions en els discursos del conflicte nigerià, al mateix temps que ignora i invisibilitza les realitats vitals de les xiquetes i les dones musulmanes al país. En segon lloc, la campanya se centra en aquestes xiquetes, fet que objectiva el seu paper com a víctimes i construeix una categoria dicotòmica (en la qual ens ubiquem 
en un dels dos extrems) sobre guerra i pau, cristiana i musulmana, víctima i perpetradora.

No obstant això, l'anàlisi política mostra punts de vista multidimensionals en què, a pesar de les vivències, aquestes joves desenvolupen decisions personals sobre la base de la seua agència relacional i la capacitat que tenen per a respondre a la violència de gènere i a la cultura patriarcal.

La societat patriarcal situa les persones en rols diversos, restringits per les oportunitats en què s'involucren, i la desigualtat de gènere insta les persones a reaccionar amb agència relacional a la competència, la solidaritat i la cooperació, fet que genera adversitat o amistats perilloses. Les xiquetes i les dones poden ser subjectes vulnerables o actors poc influents en el context local, mentre que els actors internacionals poden convertir-se en partidaris dels relators locals (evitant la perspectiva no postcolonial).

Les xarxes socials generen recursos primaris per a la mobilització $i$ originen una agenda de gènere per a combatre la violència i la sexualització. Necessitem un feminisme glocal, situat i encarnat en el moviment de base que identifique els problemes estructurals i els esdeveniments puntuals. Així doncs, les campanyes digitals han d'incloure experts locals $i$ internacionals que analitzen l'enfocament del problema i construïsquen l'estratègia de la missió principal de la campanya. L'observació dels efectes a llarg termini marcarà les accions futures. La campanya digital és només una part de la mobilització que crea consciència, reclama atenció i recursos, però la implementació de les polítiques i canvis estructurals són prioritaris per a la seua resolució.

Pel que fa a les dones i la interseccionalitat, les noves necessitats al món superen la victimització i el paternalisme cap als subjectes involucrats en el tema. En primer lloc, necessitem desconstruir el paper de les dones i els seus cossos com a instrument de la mirada masculina (universalitzat), evitant la sobreexposició dels cossos femenins en els espais públics (i, en l'àmbit digital). En segon lloc, les xiquetes, com a part del grup de dones i part de la població no adulta, són actores dels seus propis futurs. Els models a seguir de les xiquetes són importants per a guiar la població cap a missatges nous i decidir què faran els joves, cosa que reflecteix la diversitat de la població juvenil. A més, en aquest treball hem inclòs una definició crítica d'infància fundada en la prevenció de la identitat fixa i única de la seua subjectivitat, sense occidentalitzar la idea de la infància en els rols exercits per les xiquetes $i$ joves en contextos socials d'extrema violència.

\section{REFERÈNCIES BIBLIOGRÀFIQUES}

Anderlini, S. N. (2018). Challenging Conventional Wisdom, Transforming Current Practices: A Gendered Lens on PVE, Transforming Current Practice. En B. Austin i H. Giessmann Berghof (ed.) (2018), Transformative Approaches to Violent Extremism. Berlín: Berghof Foundation.

Benhabib, S. (1992). Situating the Self: Gender, Community, and Postmodernism in Contemporary Ethics, Oxford: Polity Press.

Bent, E. (2016). Making It Up Intergenerational Activism and the Ethics of Empowering Girls. Girlhood Studies, 9(3), 105-121. DOI: $10.3167 /$ ghs.2016.090308

Bloom, M. (2011). Bombshell: Women and Terrorists, Londres: Hurst.

Botha, A. i Abdile, M. (2019). Reality Versus Perception: Toward Understanding Boko Haram in Nigeria. Studies in Conflict \& Terrorism, 42(5), 493-519. DOI: 10.1080/1057610X.2018.1403152

Braidotti, R. (1994). Nomadic Subjects: Embodiment and Sexual Difference in Contemporary Feminist Theory. Cambridge: Cambridge University Press. 
boyd, d. (2014). It's Complicated: The Social Lives of Networked Teens. New Haven: Yale University Press.

Bunch, C. (2001). Women's Human Rights: The Challenges of Global Feminist and Diversity. En M. Dekoven (ed.) (2001), Feminist Locations: Global and Local, Theory and Practice (p. 129-146). New Brunswick: Rutgers.

Bustillo, J. (2017). The Case of Tumblr: Young People's Mediatised Responses to the Crisis of Learning about Gender at School. En B. Revelles-Benavente i A. M. González Ramos (ed.), Teaching Gender: Feminist Pedagogy and Responsibility in Times of Political Crisis (p. 163-177). Londres: Routledge.

Butler, J. (2009). Frames of War: When is Life Grievable? Nova York: Verso.

Carter Olson, C. (2016). \#BringBackOurGirls: Digital Communities Supporting Real-World Change and Influencing Mainstream Media Agendas. Feminist Media Studies, 16(5), 772-787. DOI: 10.1080/14680777.2016.1154887

Castells, M. (2011). Networks of Outrage and Hope: Social Movements in the Internet Age. Boston (MA): Polity Press.

Cockburn, C. (1998). The Space Between Us: Negotiating Gender and National Identities in Conflict. Londres i Nova York: Zed Book.

Coleman, R. (2018). Theorizing the Present: Digital Media, Pre-emergence and Infra-structures of Feeling. Cultural Studies, 32(3), 1-23. DOI: 10.1080/09502386.2017.1413121

Comolli, V. (2015). Boko Haram: Nigeria's Islamism Insurgency. Londres: Hurst \& Company.

Cox, K. et al. (4 de novembre de 2018). Social Media in Africa: A Double-Edged Sword for Security and Development. United Nations Development Programme. https:/www.africa.undp.org/content/rba/en/home/library/reports/ social-media-in-africa-.html

Enloe, C. (1989). Bananas, Beaches, Bases: Making Feminist Sense of International Politics, Londres: Pandora Press.

Escola de Cultura de Pau (2019). Alert 2019! Report on Conflicts, Human Rights and Peacebuilding. Barcelona: Icaria.

Friedman, E. (2016). Interpreting the Internet: Feminist and Queer Counterpublics in Latin America. California: University of California Press.

Garret, K. (2006). Protest in an Information Society: A Review of Literature on Social Movements and New ICTs. Information, Communication and Society, 9(2), 202-224. DOI: 10.1080/13691180600630773

hooks, b. (1986). Ain't I a Woman: Black Women's Rights Feminism. Londres: Pluto Press.

Khoja-Moolji, S. (2015). Becoming an 'Intimate Publics': Exploring the Affective Intensities of Hashtag Feminism. Feminist Media Studies, 15(2), 347-350. DOI: 10.1080/14680777.2015.1008747

Magallón Portolés, C. (2010). Decidir en los procesos de paz, un derecho de hombres y mujeres. ¿Qué ha aportado la resolución 1325 del Consejo de Seguridad? Papeles de relaciones ecosociales y cambio global,109, 45-56.

Magallón Portolés, C. (2020). L'extremisme violent: un repte per al feminisme pacifista. Debats: Revista de cultura, poder i societat, 134(2), 15-28. DOI: http://doi.org/10.28939/iam.debats-134-2.2.

Mahmood, O. S. (28 de març de 2017). More than Propaganda: A Review of Boko Haram's Public Messages. En ISS -Institute for Security Studies, West Africa Report. https://issafrica.org/research/west-africa-report/more-thanpropaganda-a-review-of-boko-harams-public-messages

Mandrona, A. (2016). Ethical practice and the Study of Girlhood. Girlhood Studies, 9(3), 3-19. DOI: 10.3167/ ghs.2016.090302

Matfess, H. (2017). Women and the War on Boko Haram: Wives, Weapons, Witnesses. Londres: Zed Book.

Maxfield, M. (2016). History Retweeting Itself: Imperial Feminist Appropriations of 'Bring Back Our Girls. Feminist Media Studies, 16(5), 886-900. DOI: 10.1080/14680777.2015.1116018

Mayah, E., Mariotti, C., Mere, E. i Okwudili Odo, C. (2017). Inequality in Nigeria: Exploring the Drivers. Oxfam International. https://www.oxfam.org/en/research/inequality-nigeria-exploring-drivers

Mitchell, C. (2017). Technological Nonviolence and Girls: Creating a Counter Discourse. Girlhood Studies, 10(2), 5-6. DOI: $10.3167 /$ ghs.2017.100201.

Mohanty, C. T. (1984). Under Western Eyes: Feminist Scholarship and Colonial Discourses. Boundary 2, 12 (3), $333-$ 358. DOI: 10.1007/978-1-137-07412-6_5.

Mohanty, C. T. (1991). Cartographies of Struggle: Third World Women and the Politics of Feminism. En Mohanty, C. T. (ed.) (1991). Third World Women and the Politics of Feminism (p. 51-80). Bloomington: Indiana Press.

Ordu, G. E. (2017). Trends and Patterns of Boko Haram Terrorist and Militants' Aggression in Nigeria. Aggression and Violent Behavior, 37, 35-41. DOI: 10.1016/j.avb.2017.08.006

Ponzanesi, S. (ed.) (2014). Gender, Globalization, and Violence Postcolonial Conflict Zones. Nueva York: Routledge. 
Ringrose, J. i Eriksson, K. (2011). Gendered Risks and Opportunities? Exploring Teen Girls' Digital Sexual Identity in Postfeminist Media Contexts. International Journal of Media and Cultural Politics, 7(2), 121-138. DOI: 0.1386/ macp.7.2.121_1

Riles, A. (2002). Rights Inside Out: The Case of the Women's Human Rights Campaign. Leiden Journal of International Law, 15(2), 285-305. DOI: 10.1017/S0922156502000146

Consell de Seguretat de l'ONU (2015). Security Council resolution 2225. 18 de juny de 2015. https://undocs.org/ en/S/RES/2225(2015)

Assemblea General de l'ONU (2001). Optional Protocol to the Convention on the Rights of the Child on the Sale of Children, Child Prostitution and Child Pornography. A/RES/54/263. 16 de març de 2001. https://undocs.org/es/A/RES/54/263

Yuval-Davis, N. (2006). Intersectionality and Feminist Politics. European Journal of Women's Studies, 13(3), 193-209. DOI: $10.1177 / 1350506806065752$

\section{NOTA BIOGRÀFICA}

\section{Ana M. González Ramos}

És professora contractada doctora a la Universidad Pablo de Olavide. Llicenciada en Sociologia per la Universidad de Granada l'any 1994 i doctora per la Universidad de Cádiz el 2004 (Departament d'Estadística i Investigació Operativa). Ha dirigit el grup d'investigació GENTIC: Relacions de Gènere i les Tecnologies de la Informació i la Comunicació, grup consolidat de la Generalitat (2014-2017).

\section{Beatriz Revelles-Benavente}

És professora ajudant doctora del departament de Filologies Anglesa i Alemanya de la Universidad de Granada i professora del Màster Erasmus Mundus GEMMA: Estudis de les Dones i de la Literatura de Gènere de la Universitat de Granada. És coeditora de la revista científica Matter: Journal of New Materialist Research i del llibre titulat Teaching Gender: Feminist Responsibilities and Pedagogies in Times of Political Crisis, publicat per l'editorial Routledge (2017).

\section{Verònica Gisbert-Gracia}

És doctora en Ciències Socials per la Universitat de València. Va cursar el Màster Erasmus Mundus GEMMA: Estudis de les Dones en les Universitats de Granada i Utrecht (2010). Les seues àrees principals d'investigació inclouen les accions col-lectives de dones, els estudis culturals i les polítiques dels afectes. És autora de diversos articles en revistes nacionals i internacionals, així com de capítols de llibre. 